\title{
Mito e história nas Histórias de Heródoto
}

\author{
Myth and history in Herodotus' Histories
}

\section{Camila Condilo}

\section{RESUMO}

Este artigo discute o tratamento que Heródoto dá aos mitos na obra Histórias. Tomando como ponto de partida o argumento de Robert Fowler sobre a controversa relação entre mythos e logos, sugiro que Heródoto aborda mito de uma forma coerente e sistematizada em sua narrativa. Para tanto, estabeleço uma definição de mito e analiso evidências de genealogias mitológicas nas Histórias a partir da focalização dos relatos (o do próprio autor ou o de suas fontes).

\section{ABSTRACT}

This article discusses Herodotus' treatment of myth in the Histories. Taking as a starting point Robert Fowler's argument about the controversial relationship between mythos and logos, I suggest that Herodotus presents a coherent and systematic approach of myth in his narrative. To this end, I propose a definition of myth and analyze mythical genealogies in the Histories by looking at focalization (the author's or his sources') in their reciting.

\section{PALAVRAS-CHAVE}

Heródoto; Mito; História

\section{KEYWORDS}

Herodotus; Myth; History. 
Neste artigo, discuto dois autores, um antigo e um contemporâneo: Heródoto e Robert Fowler. Usarei Fowler como uma desculpa para falar de Heródoto e Heródoto como uma desculpa para falar de Fowler, pois acredito que uma abordagem mais apurada da relação entre mito e história nas Histórias esclarece e complementa um argumento muito importante feito por Fowler sobre esta controversa relação, mas que é, em certa medida, equivocado no que diz respeito a Heródoto. Ao mesmo passo, tal abordagem também lança luzes a respeito do trato do próprio Heródoto sobre esta questão. Qual seria esse argumento? De acordo com Fowler, não existe em Heródoto um contraste semântico claro do que é mythos e do que é logos, tampouco um tratamento sistemático na operacionalização destes dois conceitos na narrativa. Posto isso, meu objetivo é tentar situar com maior precisão a atitude de Heródoto a respeito da relação entre mito (mythos) e razão (logos), a fim de fazer uma espécie de correção do que considero ser um problema nesse importante argumento de Fowler.

Antes de começar, vem a propósito contextualizar quem são esses dois autores. Embora Heródoto dispense apresentações, vale lembrar que ele foi um autor grego do século $V$ a.C. da dórica Halicarnasso (atual Bodrum no oeste da Turquia) e que ele é considerado por muitos classicistas - embora seja discutível o que se entende por História no período em que ele escreveu - como o primeiro historiador. Robert Fowler é Professor na Universidade de Bristol, na Inglaterra, e ocupa uma série de cargos administrativos importantes, dentre eles o de Presidente da Hellenic Society (2014-2017). No que diz respeito à pesquisa, Fowler tem realizado um trabalho muito importante sobre os mitógrafos gregos, dentre os quais se incluem um volume de fragmentos e outro valiosíssimo de comentário (Early Greek Mythography vols. 1 e 2), além de muitos artigos e capítulos de livro sobre assuntos diversos, tais como genealogia, religião, mundo intelectual grego, dentre outros. A questão que me interessa neste artigo é sua discussão sobre a relação mito e história. Embora Fowler tenha influenciado muito a forma como penso Heródoto hoje, tenho 
uma divergência com este aspecto específico do trabalho dele. É esse aspecto que desenvolvo a seguir, muitas vezes utilizando argumentos do próprio Fowler contra ele mesmo. Para tanto, apresentarei, primeiramente, o argumento do autor sobre a relação entre mito e razão, apontando o problema que é o ponto de partido deste artigo. Em seguida, definirei os conceitos de mito e razão que orientam minha análise. Por fim, discutirei algumas passagens das Histórias a fim de demonstrar que Heródoto aborda a relação entre mito e história de uma forma pensada e sistemática, o que vai de encontro ao argumento de Fowler sobre esta questão.

\section{Robert Fowler sobre mythose logos}

Robert Fowler revisita a polêmica tese da passagem do mythos para o logos no artigo "Mythos and Logos", publicado no Journal of Hellenic Studies, em 2011. Esta tese, cujo trabalho mais representativo é o livro de Wilhelm Nestle, Vom Mythos zum Logos (1940), e as obras de autores como Jean-Pierre Vernant, foi muito criticada até recentemente por estabelecer uma relação direta entre concepções antigas e modernas de mito e razão; uma evolução linear e simplista de um período incivilizado e primitivo para outro, dito civilizado e racional; e pelo simples fato de que mesmo na contemporaneidade mitos ainda fazem parte da vida das pessoas.

Sendo assim, sua proposta traça um histórico do uso semântico da palavra mythos e sua relação com o termo logos, cujo significado também se alterou ao longo do tempo, sempre levando em conta as complexidades das rupturas e permanências. Nesse sentido, Fowler analisa estes termos em vários autores, mas particularmente nos filósofos pré-socráticos, sofistas, Heródoto e escritores do período helenístico e imperial. A partir disso, Fowler conclui que a narrativa tradicional sobre a relação entre mythos e logos possui muitos problemas, mas que não é de toda sem fundamento: existem nas fontes antigas desde antes de Platão o reconhecimento de alguma forma de 
contraste entre estes dois termos no sentido de verdadeiro versus falso, realidade versus imaginação, argumento ficcional versus argumento lógico, bem como uma forte associação entre mito e poesia, a qual é contraposta com procedimentos críticos de investigação já no século $V$ a.C. Enquanto tais, estes aspectos correspondem claramente ao que se entende por mito e razão na tradição dita ocidental desde o Iluminismo.

Posta uma breve síntese do argumento de Fowler, cabe agora nos voltarmos para o tratamento dispensado a Heródoto no contexto desse argumento. Heródoto é um autor chave tanto para a visão tradicional sobre a questão da passagem do pensamento mítico para o racional quanto para o argumento de Fowler porque ele ilustra muito bem as características que acabei de mencionar e as dificuldades interpretativas delas decorrentes. Tanto no argumento tradicional quanto no de Fowler, Heródoto se situa no início de um processo de transformação do sentido das palavras mythos e logos e de suas implicações ideológicas. Afinal, o sentido arcaico do termo mythos e seus derivados deixa de expressar declarações de autoridade para designar exatamente o oposto. Heródoto é um dos primeiros autores em que nós percebemos uma distinção qualitativa nesse sentido. $A$ meu ver, Fowler está correto sobre este ponto.

Fowler também parece correto ao afirmar que, no sentido estrito, Heródoto não classifica as histórias que ele critica como mito, tampouco diz se elas são verdadeiras ou falsas. Heródoto apenas afirma que prefere falar do que nós podemos saber, isto é, do que pode ser conhecido através da investigação e experiência. Também concordo com o argumento de Fowler a respeito do uso que Heródoto faz desse vocabulário. Embora a insistência de Heródoto em usar logoi possa ser considerada uma tentativa deliberada de excluir mythoi de sua narrativa, nós não devemos fundamentar nossas análises em especulação, mas em evidências. E as evidências indicam que Heródoto sempre se refere tanto a seu relato ou pensamento quanto ao relato ou pensamento de outros como logos (cf. Hdt. 1.95, 2.3, $4.127,6.124,7.41)$; que Heródoto utiliza a palavra mythos 
apenas duas vezes ao longo de sua obra (Hdt. 2.23, 2.45), quando ele poderia tê-lo feito em várias ocasiões; mas que, embora tais ocorrências apareçam em contextos sugestivos de um contraste, fato é que somos nós quem chamamos as histórias que Heródoto critica de mito.

Meu primeiro ponto de divergência com Fowler é que, embora o vocabulário seja de importância fundamental tanto para a compreensão do desenvolvimento da relação entre mythos e logos quanto das implicações ideológicas a ela relacionadas, deve-se ter em mente também que a ausência de clareza no uso do vocabulário não quer dizer que o fenômeno do contraste entre as ideias que estas palavras representam já não existisse. O fato da precisão e do contraste semânticos destes dois termos não se manifestarem de forma explícita no âmbito do vocabulário parece indicar que estas ideias estão em processo de maturação, afinal, estamos falando aqui em um período de transição. Além disso, mythos ainda terá qualidades semânticas ambíguas em Platão e mesmo além - o próprio Fowler admite isso em dado momento de seu texto (FOWLER 2011, p. 63-64).

O segundo ponto, que é uma implicação do primeiro, é que não há nas Histórias um tratamento sistemático do que é mythos e do que é logos. Vejamos algumas declarações:

Suas [Heródoto] reflexões acerca de método e a decisão de restringir sua investigação (historie) à "idade dos homens" mostra que uma distinção qualitativa está tomando forma entre aquilo que pertence ou não ao domínio da história. Por outro lado, a construção não é perfeitamente articulada, tampouco aplicada de forma consistente em relação a todos os materiais antigos (FOWLER 2011, p. 52). ${ }^{1}$

Uma vez que Tucídides era bem versado nos escritos sofísticos, seu mythodes pode ser tomado como evidência adicional para a utilização que eles faziam deste conceito. Poderíamos atribuir o mesmo sentido a Heródoto? A resposta, a meu ver, é que esta consciência é explícita em Tucídides (to mythoodes) e implícita em Heródoto (FOWLER 2011, p. 61). 
No tratamento dispensado à Guerra de Tróia por Tucídides, este sentido de historicização é muito forte, estando associado com uma declaração programática explícita sobre o seu próprio projeto. Heródoto não vê a diferença com a mesma claridade; ele carece de ou não usa o termo mythoōes; ele pode ser inconsistente em seus cálculos cronológicos e (mais honestamente, alguém poderia dizer) incerto sobre um exemplo ou outro (tal como Minos); mas ele essencialmente está participando do mesmo processo que Tucídides (FOWLER 2011, p. 62).

Note que, para Fowler, Heródoto apresenta elementos racionalizantes, mas de forma não articulada, especialmente quando comparada com a sofisticação teórica e metodológica de Tucídides. No restante deste artigo, questiono esta ideia ao tentar demonstrar que Heródoto faz uma abordagem consistente e explícita dos seus (que também são os nossos) mitos, embora tal articulação não transpareça claramente formulada no uso do vocabulário.

\section{Mito e história}

Na historiografia contemporânea, mythos foi por muito tempo definido em oposição a logos. Logos é um termo que apresenta muitos sentidos ligados ao universo da linguagem e do discurso, como contação de histórias, argumento, discurso, relato, entre outros. Logos também entra na definição de várias disciplinas como zoologia, cosmologia, cronologia etc., de onde resulta sua relação com conhecimento e, portanto, com a ideia de razão. Afinal, entender a natureza de uma coisa, isto é, "o que é algo", é pré-requisito para se falar "o que algo é" (LESHER 1999, p. 244245). A ideia de mythos como contraponto ao conceito de logos é problemática por várias razões, sendo a principal delas o fato de que mythos também possui uma dimensão racional na medida em que qualquer forma de pensamento necessariamente envolve lógica, portanto, cada forma de pensar tem sua própria razão de ser. Se mythos é entendido no sentido de história não verdadeira, permanece o fato de que histórias fabulosas continuaram válidas por muito tempo como explicações relevantes para a manutenção de práticas sociais e políticas no mundo antigo. 
Diretamente relacionado com isso, há um problema de definição sobre que tipo de histórias fabulosas estamos falando. Seria mito em termos de gênero literário, tais como a poesia épica e a tragédia, de mitemas em tradições orais ou de lendas coloniais? Cada uma destas possibilidades têm implicações distintas. Por exemplo, o primeiro caso envolve formas diferentes de se enquadrar uma história ou grupo de histórias. No segundo, mitema é um termo criado pela tradição estruturalista "para denotar o irredutível, o imutável elemento central encontrado nos vários mitos", que constitui "uma função e reflexo de realidades culturais e padrões de pensamento mais amplos", tal como a história do bebê salvo miraculosamente da morte para se tornar um governante poderoso (e.g. rei persa Ciro e o tirano coríntio Cipselos). Lendas coloniais, por sua vez, contêm verdade histórica, mas essa verdade só é representada simbolicamente através de histórias antes do que através de uma análise objetiva dos fatos (BARAGWANATH; DE BAKKER 2012, p. 47-56; THOMAS 2012, p. 233-235).

Outra forma de se pensar mito é através da relação com crenças religiosas. Tal critério, no entanto, é tão problemático quanto o primeiro, na medida em que, ao contrário do cristianismo, os gregos antigos não tinham um corpus de preceitos doutrinários ou uma hierarquia clerical organizada para orientar um fórum de práticas e discussão sobre o assunto. Também não temos evidências concretas para sustentar a oposição fato e ficção. A palavra grega "verdade" (á $\lambda \hat{\theta} \theta \varepsilon ı \alpha)$ deriva da conjunção do alfa privativo com $\lambda \dot{n} \theta \omega$ ("esquecer"), que é uma forma colateral do verbo $\lambda a v \theta$ áv $\omega$ ("passar despercebido"). Antes do que uma polaridade entre "verdade" e "mentira", á $\lambda \hat{\theta} \theta \varepsilon ı$ expressa o sentido daquilo que não é obscurecido, desconhecido ou esquecido acerca do argumento em questão. Em outras palavras, á $\lambda \hat{\theta} \theta \varepsilon ı$ significa fazer a apreciação de uma situação da forma mais completa e precisa que se for capaz

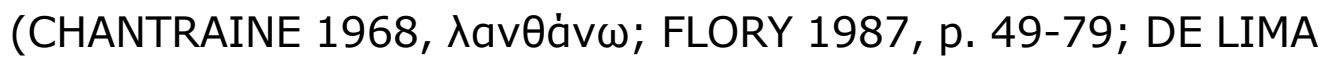
1996, p. 173-185; HARRISON 2000, 2004; CHERUBIN 2009, p. 52-58, 62; VARTO 2009, p. 38; BARAGWANATH; DE BAKKER 2012; BRANSCOME 2013, p. 6-11). 
Há, portanto, sérios problemas em se estabelecer uma correspondência direta entre a ideia de mythos e a ideia de "ficção", "falsidade" ou "mentira". Entretanto, Fowler (2011), conforme apontado anteriormente, observa os perigos de se rejeitar completamente qualquer tipo de relação possível entre os termos mythos e logos com os significados contemporâneos que atribuímos a eles, pois isto afeta de forma significativa não só nosso entendimento da cultura grega, mas também as tentativas de se historicizar a ideia de racionalidade.

Com esse pano de fundo em mente, é importante esclarecer que me refiro à relação entre mito e história nas Histórias como sinônimo de mito e razão porque, no contexto da obra de Heródoto, os indícios do que chamamos racionalidade estão intrinsicamente relacionados ao processo de sua historie. Heródoto define historie como uma atividade intelectual cuja finalidade é avaliar criticamente as informações de suas fontes obtidas através de observação, relatos orais, reflexão/julgamento pessoal e investigação (Hdt. 2.99). Por contiguidade, historie também é o resultado dessa atividade de investigação intelectual (Hdt. 1.1). Portanto, os vários logoi que constituem o logos de Heródoto são, ao mesmo tempo, ação e resultado da sua atividade de análise crítica, em outras palavras, de seu racionalismo.

Outros aspectos confirmando a relação entre historie e racionalismo são as críticas e os comentários metodológicos de Heródoto. Heródoto restringe sua investigação apenas a evidências que ele pode acessar de alguma forma: "De minha parte, não tenho nenhuma intenção de afirmar que esses eventos ocorreram dessa ou daquela maneira. Mas eu sei quem foi o primeiro homem a cometer atos injustos contra os gregos" (Hdt. 1.5); "Polícrates é o primeiro grego de que temos notícia a tentar controlar o mar, exceto, é claro, por Minos de Cnossos e qualquer um que possa ter dominado o mar antes de Minos. Mas no que é dito sobre a chamada idade humana, Polícrates foi o primeiro nesse sentido" (Hdt. 3.122). Ele dispensa os elementos supernaturais nas histórias dos heróis legendários ao colocá-las sob análise crítica: "como 
poderia ser humanamente possível para Heracles, um homem só e humano, como eles dizem, matar muitos milhares de homens de uma só vez?" (Hdt. 2.45); "Eu disse 'até Perseu' uma vez que eu não consigo traçar a linhagem além disso porque ninguém é considerado o pai mortal de Perseu - como Anfitrião, por exemplo, é considerado o pai de Heracles" (Hdt. 6.53). Heródoto também associa os poetas com a invenção de histórias: "Pois eu, ao menos, não tenho conhecimento seguro de que um rio Oceano existe. Eu penso, ao contrário, que Homero ou um dos poetas antes dele inventou o nome e o introduziu na sua poesia" (Hdt. 2.23); "Pois eu acredito que Hesíodo e Homero... foram os poetas que compuseram para os gregos a genealogia dos deuses..." (Hdt. 2.53). Além de confirmar a estreita relação entre razão e historie, estas são evidências sugestivas de que histórias tinham valores diferentes e que Heródoto parece privilegiar certos tipos de histórias sobre outros. Olhemos com mais vagar este ponto.

Embora Heródoto utilize historie para examinar histórias fabulosas, ele não parece ter problemas em acomodar elementos extravagantes no seu relato sobre as localidades e costumes de outros povos, tais como no caso das formigas gigantes que coletavam ouro para os indianos (Hdt. 3.102) ou no das serpentes aladas que tomavam conta das árvores de olíbano na Arábia (Hdt. 3.107). Apesar de suas críticas ao divino, sua narrativa é permeada por tais elementos, como declarações oraculares, portentos, sonhos premonitórios etc. Além disso, como Heródoto poderia ter sabido sobre conversas privadas, tal como o diálogo noturno entre Dario e Atossa no aposento real persa (Hdt. 3.132-3.134)? Se fossemos seguir estritamente a metodologia de Heródoto, estas histórias são todas mitos na medida em que elas não podem ser verificadas.

Contudo, elas constituem uma forma elaborada através da qual Heródoto tenta compensar a ausência de evidências em seus argumentos ao apelar para uma apresentação realística de conjecturas como prova de sua honestidade intelectual e comprometimento com a pesquisa. Em outras 
palavras, Heródoto está aplicando nesses casos um argumento eikos. Eikos ( (íkós, lon. oíкós) é uma palavra grega geralmente traduzida como "provável", "razoável", "usual" e é indicadora de pensamento sofístico na medida em que é um argumento construído para persuadir através de verossimilhança antes do que através de declaração direta de verdade. Defender uma ideia baseando-se em probabilidade envolve mais do que um argumento lógico baseado em fatos. Envolve construir um argumento não só a partir do que é mais provável, mas principalmente a partir do que é geralmente o caso. Eikos evoca um sentido fortemente normativo na medida em que depende da manipulação de estereótipos do que é normal. Assim, um orador ganha a audiência ao apresentar como evidência uma suposição que é geralmente aceita, mas não explicitamente declarada, muito menos provada (GOLDHILL 2002, p. 49-50; cf. GRIMALDI 1980; GAGARIN 1994, p. 46-68; DE LIMA 1996, p. 70-76, 127-170). De acordo com a definição de Kraus:

Em última instância, o que faz um argumento eikos convincente não é sua semelhança com alguma verdade ontológica (que, de acordo com Górgias, é inalcançável de qualquer maneira), mas o grau de coerência e congruência que a narrativa de um orador tem com a experiência cotidiana ordinária da audiência, com suas predisposições emocionais e hábitos de comportamento (KRAUS 2006, p. 141-142).

A linha de argumento do orador deve, dessa maneira, ser adaptada ao que a própria audiência sentiria ou faria em circunstâncias similares ou como outros personagens parecidos tenderiam a se sentir ou agir em situações e condições análogas. Esta adaptação para antecipar resposta, penso, é o que é expresso pelo sentido de conveniência e apropriabilidade expressos semanticamente pela palavra cikós (KRAUS 2006, p. 141-142).

A partir disso, formigas escavadoras de ouro e serpentes aladas são críveis porque se concentram nas fronteiras do mundo conhecido, das quais as pessoas não têm (ou têm apenas muito pouca) informação. Por serem lugares dos quais se sabia muito pouco, acreditava-se que coisas muito estranhas aconteciam lá. Manifestações divinas também eram 
críveis na medida em que eram conectadas a provas visuais de fenômenos naturais, como no caso da epifania do deus Apis no Egito, reconhecida através de certas marcas distintivas no corpo de um bezerro (Hdt. 3.28). Conversas noturnas entre esposos e as implicações políticas delas decorrentes quando ocorrem entre pessoas poderosas, também fazem sentido, pois apelam para um padrão familiar à rotina da audiência. Menos usual, no entanto, é encontrar os deuses que os gregos antigos cultuavam em carne e osso, interagindo diretamente e tendo filhos com seres humanos.

Esses exemplos sugerem que, quando Heródoto passa mitos pelo crivo de sua historie, ele tem como alvo um tipo específico de mito, os quais acredito ser uma série de histórias sobre o passado focada em deuses e heróis e notadamente consolidada no imaginário social e universo intelectual gregos. Além da crítica das mentes imaginativas dos poetas, existem dois outros pontos corroborando minha hipótese. Primeiro, poetas como Arion (Hdt. 1.23-1.24), Ésquilo (Hdt. 2.156) e Simonides (Hdt. 5.102, 7.228) são geralmente citados explicitamente apenas como personagens em histórias. ${ }^{2} \mathrm{Em}$ contraste, Heródoto parece admitir Homero e Hesíodo como autoridades textuais. Homero e Hesíodo eram os poetas que deram forma literária a muitas crenças e costumes do universo grego, mesmo a muito do repertório dos outros poetas. Por conta disto, Heródoto não se satisfaz em mencionar estes dois autores apenas. Ele demonstra uma necessidade de discutir suas ideias abertamente e o faz em muitas ocasiões (e.g. Hdt. $2.53,2.82,4.32$ ). Isso não se restringe às passagens nas quais Heródoto os nomeia explicitamente. O diálogo de Heródoto com a tradição mítica que Homero e Hesíodo inauguraram por escrito - pois muitas das histórias por eles contadas já circulavam oralmente bem antes disso - é muito mais sutil e profundo, transcendendo declarações explícitas. Nesse sentido - e este é meu segundo ponto -, Heródoto é bastante consciente de que o tipo de história que ele deseja contar será avaliado de acordo com critérios exteriores ao mundo da contação de histórias, de maneira que ele anuncia de antemão no proêmio
2. Píndaro (Hdt. 3.38)

é a única exceção.

Para um inventário

das menções de

poetas em Heródoto,

ver Lateiner (1989,

p. 106-107). É

importante ter em mente, contudo,

que presença ou ausência de um nome não constitui prova conclusiva de que Heródoto está ou não dialogando com ideias de um autor. 
os princípios que tanto orientam seu trabalho como servem de critérios a partir dos quais seu trabalho deve ser avaliado pela audiência: seu foco "nas coisas feitas pelos homens" (тà yદvópદva

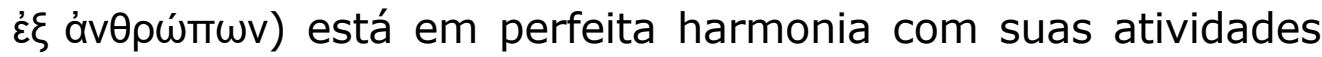
de criticismo literário da poesia homérica e hesiódica. Tomando como base as evidências elencadas sobre os argumentos pro e contra o racionalismo de Heródoto, fica evidente que a crítica que Heródoto faz ao mythos tem como alvo as histórias sobre deuses e heróis legendários que nós encontramos não só nestes dois poetas, mas também em outros poetas e autores (como os mitógrafos, por exemplo) que seguiram seus passos, ao mesmo tempo em que ele dificilmente demonstra qualquer preocupação em desafiar outros tipos de histórias que seriam igualmente consideradas como mitos aos olhos contemporâneos.

Por essas razões, eu adoto a definição de mito proposta por Baragwanath e de Bakker (2012, p. 10-19), os quais sugerem três características distintivas de mito: 1 . deuses e heróis são os principais assuntos do mito, independentemente de seu formato narrativo; 2 . mito é tradicional na medida em que não pode ser atribuído a um autor específico, aparecendo em diferentes trabalhos e gêneros. Autores eram livres para colorir a história como quisessem, mas "eram sempre atrelados em alguma medida pelas tradições que determinavam o esqueleto da narrativa e os limites dentro dos quais motivos podiam variar" (BARAGWANATH; DE BAKKER 2012, p. 17); 3. Mitos tinham um importante significado coletivo para grupos sociais na medida em que eram parte de um repertório mais amplo de histórias que poderiam, por exemplo, "formar a consciência grega acerca de sua história e da relação entre os vários grupos" (BARAGWANATH; DE BAKKER 2012, p. 18).

Estabelecidos os parâmetros da discussão, tomarei como estudo de caso as genealogias dos heróis gregos, pois elas parecem ilustrar de forma contundente não só um contraste entre mito e história nas Histórias, mas também uma sistematização na operacionalização destes dois conceitos, independentemente de sua formulação explícita em nível de vocabulário. 


\section{Mito e história nas Histórias de Heródoto}

De acordo com os critérios acima, são 15 as genealogias míticas nas Histórias: ${ }^{3}$

\begin{tabular}{|c|l|}
\hline Genealogia & \multicolumn{1}{|c|}{ Localização nas Histórias } \\
\hline Io & 1.1 \\
\hline $\begin{array}{c}\text { (Paris) Alexan- } \\
\text { dre }\end{array}$ & $\begin{array}{l}1.3,2.120 \text { (nesta ocorrência aparece junto com } \\
\text { seu irmão, Heitor) }\end{array}$ \\
\hline Midas & $1.14,8.138$ \\
\hline Minos & $\begin{array}{l}1.173 \text { (nesta ocorrência aparece junto com seu } \\
\text { irmão, Sarpedão), 3.122, 7.169-7.171 }\end{array}$ \\
\hline Heracles & $2.43-2.45,2.145-2.146,6.53-6.54$ \\
\hline $\begin{array}{c}\text { Castor e Poli- } \\
\text { deuces }\end{array}$ & $2.43,2.50,4.145,5.75,6.127,9.73$ \\
\hline Melampo & 2.49 \\
\hline Perseu & $2.91,6.53-6.54,7.61,7.150$ \\
\hline Helena & 2.112 \\
\hline Targitau & 4.5 \\
\hline Édipo & $5.59-5.60$ \\
\hline Danae & $6.53-6.54$ \\
\hline Pelops & $7.11,7.159$ \\
\hline Medéia & 7.62 \\
\hline Agamemnon & 7.159 \\
\hline &
\end{tabular}

3. Iniciei discussão evidências questões levantadas, de forma aprofundada, Condilo (2017). uma dessas das elas mas pouco em

Essas 15 genealogias se distribuem em 26 passagens ao longo do texto, sendo que oito delas (Io, Melampo, Helena, Targitau, Édipo, Danae, Medéia e Agamemnon) são referidas apenas uma vez. Na maioria delas, Heródoto faz uso da primeira pessoa autoral, seja como historiador, narrador ou comentarista (DE JONG 2004, p. 103). Não raro, ele utiliza mais de uma ou todas estas modalidades autorais em uma mesma passagem. Em duas ocorrências, no entanto, isto não acontece: as genealogias de Pelops e Agamemnon.

A genealogia de Pelops aparece em um discurso no qual Heródoto supostamente reproduz em citação direta as palavras de Xerxes, tendo um sentido pejorativo ao se referir aos peloponésios como descendentes de um escravo:

...Xerxes, enfurecido com o que ele havia dito, respondeu, 
"...Mas uma vez que nós persas fomos os primeiros a serem ofendidos, é correto e apropriado que nós os punamos agora, a fim de que eu possa realmente aprender essa coisa terrível que sofrerei quando marchar contra esses 'homens' os quais Pelops o frígio, um escravo dos meus antepassados, conquistou tão decisivamente que mesmo hoje esse povo e sua terra mantêm o nome de seu conquistador" (Hdt. 7.11, grifo meu).

A mesma genealogia aparece em um discurso no qual Heródoto supostamente reproduz, também em citação direta, as palavras de um espartano. Nesse caso, a referência genealógica tem uma conotação positiva, pois Pelops é valorizado como herói fundador do Peloponeso através da figura de Agamemnon:

Nesse momento, Siagro não pôde suportar ouvir isso e respondeu, "Bem, tenho certeza de que Agamemnon descendente de Pelops se voltaria em seu túmulo em alto lamento se ele ouvisse que os espartanos estavam sendo roubados de seu comando por Gelão e os siracusanos!" (Hdt. 7.159, grifo meu).

Embora essas duas passagens sejam exceção por não aparecerem na primeira pessoa autoral, mas em citações em "discurso direto" dos personagens do relato do autor, elas concordam com a maioria das ocorrências ao estabelecer uma espécie de corte entre tempo divino e tempo histórico. Vejamos melhor como funciona a presença deste corte cronológico.

Em nossa primeira referência genealógica, Io é apresentada como filha de Ínaco. Embora as diferentes tradições ora considerem Ínaco como um deus-rio filho de Oceano e Tétis, ora como o primeiro rei mortal de Argos (e.g. Apollod. Bibl. 2.1; Paus. 2.15), Heródoto considera Ínaco um rei mortal. Isso fica evidente não só pelo enunciado do proêmio de sua obra ser seguido pela busca de uma explicação plausível sobre a origem do conflito entre gregos e bárbaros (contexto no qual esta passagem se insere), mas principalmente pelo fato de Heródoto claramente se referir a Io a partir de evidências resultantes de seu trabalho de investigação no presente:

Os sábios persas dizem ( $\varphi$ aбi) que os fenícios foram a causa da disputa. Os fenícios chegaram ao nosso mar a partir do mar que 
é chamado Vermelho e tendo se estabelecido no território que

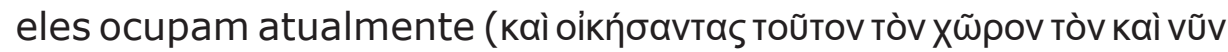

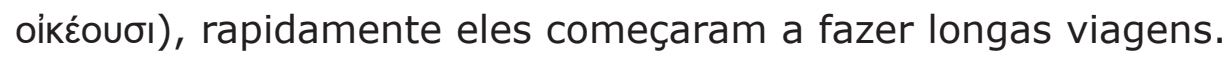
Dentre os outros lugares para os quais eles levaram mercadoria egípcia e assíria, eles chegaram a Argos, que naquela época era proeminente em todos os aspectos dentre os povos do que hoje

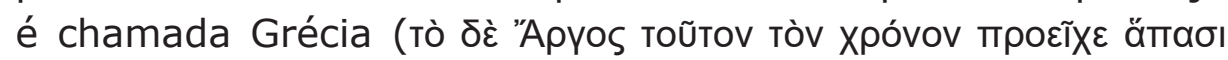

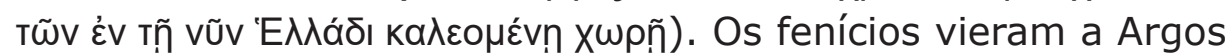
e expuseram suas mercadorias. No quinto ou sexto dia depois de sua chegada, quando suas mercadorias já estavam quase todas vendidas, muitas mulheres vieram à orla, dentre elas, especialmente, a filha do rei. Seu nome, de acordo com o que

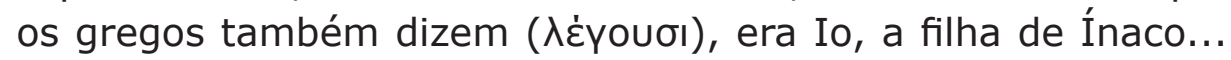
(Hdt. 1.1).

O tempo dos homens como corte cronológico se fundamenta no uso de fontes, caracterizado especialmente pela presença dos verbos pađì ("declaram", "dizem", "afirmam") e $\lambda \dot{\varepsilon}$ үouбı ("falam", "dizem"). Tais verbos dão uma espécie de concretude ao argumento de Heródoto, pois são a base a partir da qual ele o constrói. Mas a concretude de seu argumento também é reforçada por relações de comparação e contraste com elementos do tempo presente, particularmente através da utilização do advérbio vũv ("agora", "tempo presente"): "ocupam atualmente"; "do que hoje é chamada Grécia". Enquanto tal, este referencial temporal se contrapõe ao tempo dos deuses ao qual Heródoto não tem acesso. Nesse sentido, o fato de Heródoto apresentar Ínaco como um mortal é bastante coerente com o contrato textual que ele estabelece com seus leitores no começo de seu trabalho, bem como com sua abordagem metodológica ao longo das Histórias.

Tal abordagem é ainda mais clara no tratamento que Heródoto dispensa à genealogia de Heracles. Também baseandose nos resultados de sua investigação, Heródoto argumenta que existem dois Heracles: um que é um deus egípcio muito antigo e outro que é um herói grego (Hdt. 2.43-2.45). Além disso, ele diz que alguns gregos mantêm dois santuários distintos para Heracles, sacrificando para um Heracles imortal com o epíteto "Olímpico" e para um Heracles herói, que é mortal. Este, no entanto, recebe oferendas próprias de um morto, 
não de um deus. Mais significativo do que a separação entre os Heracles mortal e imortal é que esta é uma implicação do fato de que Heródoto se restringe a falar sobre aquilo que ele tem evidências para investigar e discutir, o que também se evidencia no trecho a seguir:

No que diz respeito a esses dois (Pan e Dioniso), uma pessoa pode escolher qualquer dessas histórias que achar mais crível. De qualquer maneira, minha opinião pessoal já foi revelada. Se Dioniso filho de Semele e Pan filho de Penélope apareceram na Grécia e lá envelheceram, como Heracles filho de Anfitrião, nós poderíamos dizer que eles também eram apenas homens que foram nomeados a partir de Pan e Dioniso, deuses muito antigos (Hdt. 2.145-2.146).

Portanto, não há uma divisão entre tempo divino, mítico e histórico, mas apenas um tempo divino e um tempo histórico nas Histórias.

Tal aspecto não se evidencia apenas nas genealogias de Io e Heracles. Muitas das outras genealogias consistentemente mencionam os pais mortais dos heróis e heroínas do passado antes do que seus progenitores divinos. Perseu (Hdt. 2.91, 6.53) e os irmãos Minos e Sarpedão (Hdt. 1.173) são apresentados por meio de suas mães mortais Danae e Europa, respectivamente. Helena (Hdt. 2.112) e os gêmeos Castor e Polideuces são introduzidos por meio de seu pai mortal, Tindário (Hdt. 4.145, 5.75, 9.73), bem como Midas (Hdt. 1.14, 8.138) e Agamemnon (Hdt. 7.159). Entretanto, Heródoto deixa em aberto a ancestralidade de Pelops (Hdt. 7.11, 7.159). De todo modo, haja vista o padrão que estamos acompanhando, há grande possibilidade de que ele não conecta Pelops a um deus porque ele não considera isso importante. Mais do que isso, ele não parece considerar uma relação como esta razoável ou "racionalmente" aceitável.

Mas há exceções. Se em Hdt. 2.91 e 6.53 Perseu é apresentado como filho de Danae apenas, em Hdt. 7.61 e 7.150 Perseu é filho de Danae e Zeus. Se em Hdt. 4.145, 5.75 e 9.73 Castor e Polideuces são filhos de Tindário, um mortal, em Hdt. 2.43 
e 2.50 eles são explicitamente chamados de deuses, portanto, filhos de Zeus. Isto sem contar que a própria terminologia com a qual eles são referidos já é indicativo de um problema em nosso recorte, uma vez que Dioscuri significa "filhos de Zeus". Targitau, por exemplo, não aparece como filho de pais mortais, como nos casos que vimos antes, mas como filho de Zeus e da filha do rio Borístenes (Hdt. 4.5). Além disso, o corte entre tempos divino e histórico também é posto em xeque na genealogia de Minos. Se em Hdt. 1.173 Minos é introduzido como filho de Europa apenas, em Hdt. 3.122 há um contraste nítido entre Minos como figura mítica em contraposição a Polícrates como figura histórica. Como explicar tais contradições dentro do esquema delineado acima, de que Heródoto delimita seu comentário sobre esses personagens tendo como base as evidências que ele pode examinar, o que o leva a adotar o critério de pais mortais como corte de referência em sua cronologia? Olhemos para esses casos individualmente para tentar entender o que está acontecendo.

Começo com a genealogia de Targitau, que demanda uma explicação um pouco mais simples do que as ambiguidades nas genealogias de Perseu, dos gêmeos Castor e Polideuces e de Minos. A genealogia de Targitau aparece em um contexto no qual Heródoto oferece uma genealogia explicando as origens do povo cita. Destaca-se nessa passagem sua atitude como historiador, pois ele se esforça em oferecer todas as explicações a que teve acesso em sua investigação, bem como realiza uma análise crítica de todas elas, no intuito de indicar a mais plausível (Hdt. 4.54.12). Nesse sentido, ele relata três versões da genealogia dos citas: uma dos próprios citas, outra dos gregos que habitam a região do Ponto Euxino (Mar Negro) e uma contada igualmente por gregos e bárbaros da qual Heródoto se diz mais parcial. Assim, a versão da genealogia de Targitau como filho de Zeus e uma das filhas do Rio Borístenes é apenas uma das três versões oferecidas. A focalização desta versão não é em Heródoto, mas nos citas, uma vez que esta é a versão deles sobre sua própria genealogia (üc $\delta \dot{\varepsilon}$

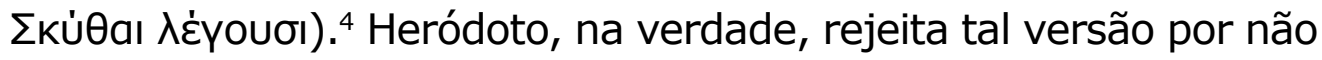

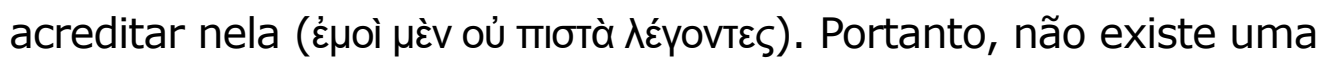
inconsistência no padrão de tratamento do mito nesta passagem.
4. Focalização, grosso modo, diz respeito à percepção de quem a história é contada, isto é, o próprio autor ou um dos seus personagens. Ela é muito mais do que "ponto de vista", pois este sugere mais uma ideia de perspectiva física do que mental (emocional intelectual). diferentes ou de subfocalização, mas elas não são pertinentes para 0 problema em questão, pois embora eu utilize certos instrumentos da narratologia para pensar o problema deste artigo, minha abordagem não é uma abordagem narratológica. narratologia característica principal o estudo de estratégias narrativas e regularidades diversas que se repetem em vários textos e este não é meu intento aqui. 
Vejamos agora as inconsistências na genealogia de Perseu que ora é referido como filho de Danae apenas (Hdt. 2.91, 6.53), ora como filho de Danae e Zeus (Hdt. 7.61, 7.150). Em 2.91, a referência a Perseu aparece em um contexto no qual Heródoto diz que os egípcios evitam adotar costumes estrangeiros, com exceção dos egípcios da cidade de Chemmis, onde há um "santuário de Perseu filho de Danae". A partir disso, ele faz um extenso relato falando do templo, do culto e das relações dos chemitas com Perseu, no qual se inclui o argumento de que Perseu seria originário daquela cidade. Além da primeira pessoa autoral, esta passagem conta com a construção "quando eu perguntei por que" (

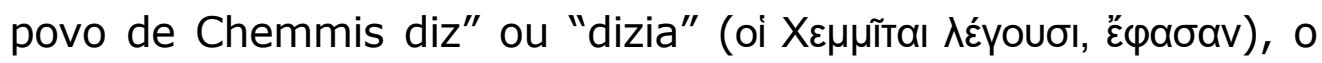
que é indicativo dos procedimentos críticos do autor. Heródoto parece ser favorável ao relato dos egípcios de Chemmis sobre Perseu porque em vários momentos ao longo do Livro 2 ele traz à tona sua polêmica teoria de que vários elementos e personagens da cultura grega são originários do Egito (Hdt. 2.2-2.4, 2.43, $2.50,2.146)$. Outro momento em que esta teoria se evidencia é a passagem a seguir, onde os procedimentos investigativos de Heródoto estão claramente em ação, bem como a relação de Perseu com sua progenitora mortal apenas:

Dos helenos, os lacedemônios são os únicos que contam essa versão da história. No que eu escrevo eu sigo o relato dos outros helenos e entendo que eles contam corretamente os reis dórios até Perseu filho de Danae, omitindo o deus e mostrando que esses reis eram helenos e que mesmo naqueles primeiros dias eles já eram classificados como gregos. Eu disse "até Perseu" e não levei o assunto para além disso porque ninguém é considerado o pai mortal de Perseu tal como Anfitrião é considerado o pai mortal de Heracles. Portanto, eu estava certo em dizer "até Perseu". Mas se alguém fosse recontar os ancestrais de Danae filha de Acrísio e listando-os em uma sequência contínua, ficaria evidente que os líderes dos dórios são genuinamente egípcios por descendência direta (Hdt. 6.53-6.54).

Note que há um corte cronológico claro no tratamento de Heródoto sobre Perseu quando ele diz que não levará o assunto adiante por não saber quem é o pai mortal de Perseu. Note também que indica uma anuência ao argumento chemita sobre 
as origens de Perseu, agora não mais em primeira pessoa autoral como narrador mas como historiador, ao afirmar que uma análise cuidadosa da evidência deixaria claro que os reis dórios eram, na verdade, de origem egípcia. Isso porque Heródoto se refere a Danae especificamente como filha do rei argólida Acrísio. De acordo com a tradição mítica (Apollod. Bibl. 2.1.4-2.2.1), Acrísio é um descente de Linceu, um outro rei de Argos que, de acordo com os chemitas, era de ascendência egípcia:

Quando eu perguntei por que Perseu aparecia apenas para eles e por que, ao contrário de todos os outros egípcios, eles celebravam com jogos atléticos, eles me disseram que Perseu era originário de sua cidade, pois Danaus e Linceu, ambos de Chemmis, viajaram para a Grécia e a partir deles é traçada a linhagem da qual descende Perseu (Hdt. 2.91).

Um elemento importante de Hdt. 6.53-6.54 é que Heródoto também menciona uma terceira versão da genealogia de Perseu ao final de seu argumento. Ele não chega a desenvolver esta parte da análise, mas ela é deveras significativa para nosso entendimento do que acontece em Hdt. 7.61, onde Perseu aparece genealogicamente ligado a Zeus. Diz Heródoto:

Assim eu tracei a genealogia dos reis espartanos de acordo com a versão grega, mas a versão dos persas é que Perseu era de origem assíria e que ele se tornou grego, o que seus ancestrais não eram. Os persas dizem que os antepassados de Acrísio não tinham vínculo algum de parentesco com Perseu, e que eles na verdade eram, como dizem os próprios gregos, egípcios ( $\mathrm{Hdt}$. 6.53-6.54).

Em Hdt. 7.61 também é usada a primeira pessoa autoral, mas a ênfase é mais em sua pessoa autoral como narrador e comentarista do que como historiador, de maneira que o vocabulário e procedimentos característicos de sua historie, tal como vimos nas passagens anteriores, quase não aparecem aqui:

Em tempos antigos, os persas eram chamados cefenes pelos

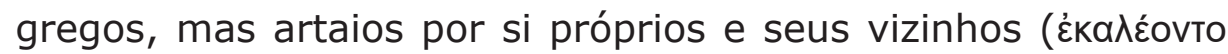

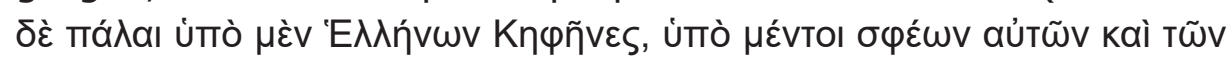

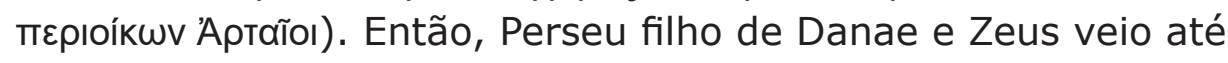
Cefeu filho de Belo e obteve Andrômeda filha de Cefeu como sua 
esposa e ela the gerou um filho que foi dado o nome de Perses e ele o deixou lá, pois Cefeu não tinha um herdeiro homem. Foi desse Perses que os persas obtiveram seu nome (Hdt. 7.61).

Embora não haja propriamente verbos legetai nesta

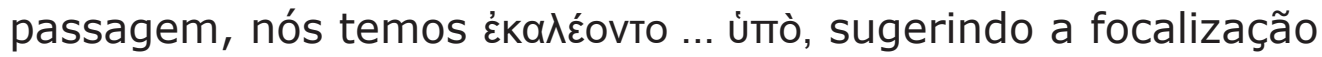
do relato como sendo a opinião de suas fontes. Mas há indícios claros de que Heródoto não está relatando sua própria opinião, mas a de terceiros nesse contexto. Primeiramente, porque em Hdt. 6.53-6.54 ele argumenta de forma contundente que Perseu é de origem egípcia e que sua investigação se restringe à linhagem mortal de Perseu. Em segundo lugar, porque em Hdt. 6.53-6.54 ele claramente focaliza o argumento da origem assíria de Perseu como sendo dos próprios persas: "mas a versão dos persas é que Perseu era de origem assíria e que ele se tornou grego". Em terceiro lugar, porque tanto as genealogias dos medos quanto as dos persas estão intimamente relacionadas com cidades acusadas de medismo durante as Guerras Médicas, quais sejam, Argos e Tebas, o que tem implicações políticas de grande importância (VANNICELLI 2012). Neste caso, a evidência de que esta é a versão dos persas e dos inimigos de Argos (possivelmente os espartanos, mais especificamente), antes do que do próprio Heródoto, é o fato de que a referência a Perseu e sua relação com os persas é retratada por Heródoto nas palavras do próprio rei persa Xerxes, supostamente em discurso direto:

Homens de Argos, esta é a mensagem do rei Xerxes para vocês: "É nossa crença tradicional de que somos descendentes de Perses, cujo pai era Perseu filho de Danae e cuja mãe era Andrômeda filha de Cefeu. Se este é o caso, nós seríamos seus descendentes e seria inapropriado para nós marchar contra nossos próprios antepassados ou para vocês se tornarem nossos oponentes ao ajudar outros contra nós; ao contrário, vocês deveriam permanecer tranquilos e em paz. Pois se tudo acontecer como planejo, não terei nenhum outro povo em mais estima do que vocês" (Hdt. 7.150; cf. 7.61).

Dessa forma, não há uma contradição na atitude de Heródoto no que diz respeito à genealogia de Perseu. A variação da focalização nessas quatro passagens revela que Heródoto 
é bastante coerente no tratamento dessa genealogia: o corte analítico são os antepassados mortais do herói. A introdução de Zeus na história se dá por conta de outras versões da genealogia que Heródoto, autor sério que é, não deixa de relatar. Seu relato, no entanto, é cuidadosamente articulado através de historie, que marca de forma clara como o leitor deve entender sua posição no debate.

A aparente contradição nas referências a Castor e Polideuces ora como filhos de Tindário, ora como deuses (filhos de Zeus) também se esclarece através de uma análise cumulativa das evidências. Heródoto se refere aos Dioscuri como deuses explicitamente em Hdt. 2.43 e 2.50; explicitamente como filhos de Tindário em Hdt. 4.145, 5.75 e 9.73; e com nenhuma referência à ascendência divina ou mortal em Hdt. 6.127. Em todas estas passagens Heródoto faz uso de primeira pessoa autoral, mas há uma distinção entre as duas passagens nas quais Castor e Polideuces aparecem como deuses e as outras quatro passagens: elas são mencionadas em momentos nos quais Heródoto aborda temas polêmicos, ao passo que, nas outras, Heródoto se coloca mais como narrador e comentarista. Além disso, esta mudança de modalidade autoral parece refletir uma evolução no argumento. Em 2.43, Heródoto faz um paralelo entre os nomes dos deuses gregos e egípcios para elaborar sua polêmica teoria, já referida anteriormente, de que os gregos se apropriaram de muitos aspectos da cultura egípcia. Mais adiante, Heródoto dá continuidade à polêmica, ainda se referindo a Castor e Polideuces como deuses e concluindo que:

De fato, os nomes de quase todos os deuses vieram para a Grécia do Egito. Pois eu estou convencido pela minha investigação de que eles vêm de lugares estrangeiros e acredito que vieram principalmente do Egito. Exceto os nomes de Poseidon e Dioscuri, como eu já havia dito, e Hera, Hestia, Themis, as Graças e as Nereidas, os nomes de todos os deuses já existiam no Egito. Aqui eu estou relatando o que os próprios egípcios dizem. Os deuses cujos nomes eles dizem não conhecer foram, acredito, nomeados pelos pelasgos, com exceção de Poseidon, uma vez que este deus foi introduzido aos gregos pelos líbios. Nenhum outro povo além dos líbios tem tido o nome de Poseidon desde 
o começo e eles têm sempre honrado esse deus. Não é costume dos Egípcios prestar honra alguma a heróis (Hdt. 2.50).

A declaração de que os egípcios não prestam honra a heróis é um ponto chave desta passagem, pois uma vez estabelecida tal diferenciação, Heródoto se refere a Castor e Polideuces ou como filhos de Tindário apenas ou sem nenhuma referência paterna em Hdt. 6.127. Tendo em consideração o argumento como um todo, é como se Heródoto estabelecesse a relação com o divino como ponto inicial de reflexão para facilitar o entendimento de sua teoria. Uma vez expostas as similaridades, é como se ele se voltasse para os contrastes e, finalmente, para as rupturas, que são o ponto em que ele queria chegar desde o início: Castor e Polideuces são heróis e não deuses, portanto, mortais. Eis o corte entre os tempos divino e humano mais uma vez.

O caso de Minos é um pouco mais complicado do que o de Targitau, Perseu e Castor e Polideuces, pois, embora Hdt. 1.173 siga a divisão cronológica padrão (divino $x$ humano), há um contraste marcado entre Minos como figura mítica e Polícrates como seu contraponto histórico no que diz respeito ao domínio dos mares:

Polícrates é o primeiro grego de que temos notícia a tentar dominar o mar, excetuando, é claro, Minos de Cnossos e qualquer um que possa ter dominado o mar antes de Minos. Mas a respeito do que é dito sobre a o tempo dos homens, Polícrates

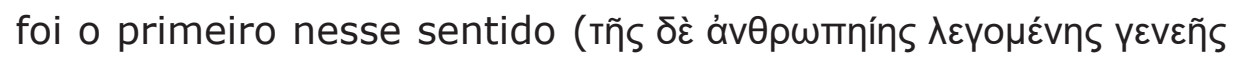

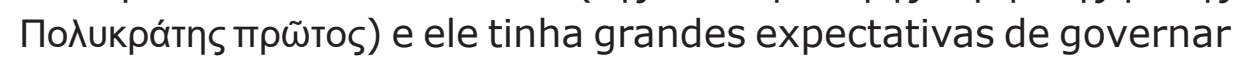
a Jônia e as ilhas (Hdt. 3.122).

Tal ênfase também é reforçada no uso do vocabulário, pois

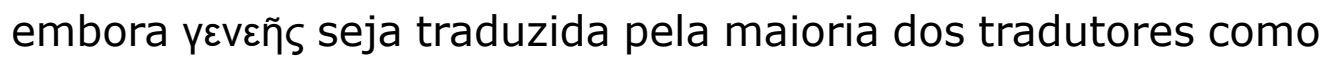

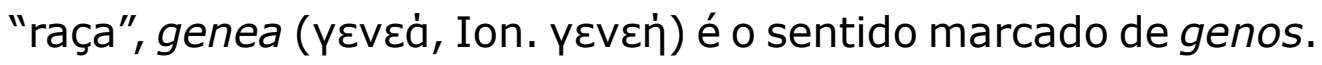
Enquanto tal, a ênfase é no sentido de geração, portanto, na dimensão temporal de genos, que tem um sentido bem mais abrangente do que genea, incluindo o de raça. Genea, por outro lado, aparece apenas no sentido temporal em Heródoto (1.3, $1.7,1.184,2.44,2.100,2.142,3.48,4.105,4.147,4.163$, $5.28,6.86 a, 6.98,6.126,7.171)$. 
Note, no entanto, que apesar da ênfase no contraste entre esses dois personagens, Heródoto não desenvolve a comparação. Antes, Minos funciona como uma espécie de "deixa" ou "elemento introdutório" para seu relato sobre Polícrates. Note também que o desenvolvimento da narrativa de Polícrates sugere a ideia de que Heródoto tenta inseri-lo no modelo trágico de ascendência e derrocada, o qual tem implicações políticas bastante importantes para a mensagem que o autor visa expressar, especialmente no que diz respeito aos efeitos nocivos do imperialismo, conforme aponta Munson (2012). O trecho da narrativa de Heródoto enfatiza a ganância de Polícrates por dinheiro e poder e é bastante ilustrativa dessa ideia. Assim, esses fatores indicam que o único desvio no tratamento que Heródoto faz dos mitos é intencional e deliberado, antes do que prova de sua abordagem pouco sistematizada sobre a questão. A historie e a habilidade literária herodotianas estão sendo conjuntamente manipuladas na narrativa sobre a vida de Polícrates, levando a cabo o contrato textual que Heródoto estabelece com seus leitores logo no começo das Histórias, qual seja, ele falará sobre os feitos realizados pelos homens (proêmio) tendo como base o princípio da instabilidade da condição humana (Hdt. 1.5).

É importante observar que o próprio Fowler admite esta divisão cronológica e suas implicações no seu Gods in early Greek historiography (2010). Contudo, a despeito de ser mais um artigo brilhante dentre os muitos trabalhos que ele escreveu, ainda assim ele argumenta que "a distinção entre mito e história reside no futuro, mesmo se ela estivesse começando a tomar forma nos dias de Heródoto, devido não somente a seus esforços, mas também aos dos sofistas" (FOWLER 2010, p. 321). Parece que a resistência de Fowler em admitir que Heródoto já está em uma fase muito mais amadurecida no desenvolvimento dessas ideias, tanto quanto Tucídides, é resultante do fato de que ele foca em um processo muito mais amplo, de um histórico dessa relação em nível de movimento intelectual. Isto sem dúvida é algo da maior importância e mérito. Entretanto, abordagens macro como dele, por sua própria natureza, nem 
sempre dão conta das particularidades de um fenômeno em obras específicas. Se Heródoto é um ponto chave de transformação no desenvolvimento semântico desses dois termos, nós não podemos deixar de olhar para sua obra com mais atenção a fim de tentar entender sua inserção efetiva nesse processo, fazendo os ajustes necessários na teoria de Fowler.

\section{Conclusāo}

Pensar um histórico do desenvolvimento semântico dos termos mythos e logos não necessariamente precisa passar pela subordinação de um autor por outro, especialmente no que diz respeito a Heródoto e Tucídides. Fowler leva em consideração o contexto cronológico, mas foca no engajamento intelectual com ideias no seu tratamento dos sofistas. No âmbito da história, no entanto, ele parece sugerir uma linha de desenvolvimento que toma como base autores representativos subordinando um a outro. A base de seu argumento em relação a isso é a ausência de explicitação do contraste entre mito e razão no uso que Heródoto faz desse vocabulário e seu consequente tratamento pouco sistemático dessa dicotomia. Contudo, a explicitação do contraste semântico é apenas um indício, muito importante, devemos admitir, mas apenas um entre outros no desenvolvimento da controversa relação entre mythos e logos ao longo do tempo. Conforme espero ter demonstrado, o tratamento de mito e razão em Heródoto é bastante consistente e independe da definição explícita do contraste no uso que ele faz destes termos.

A análise das evidências também leva à conclusão de que a focalização é um elemento da maior relevância no entendimento da manipulação das ideias de mythos e logos nas Histórias, pois ela impacta de forma significativa no sentido da genealogia ao estabelecer uma distinção entre o mito tal como era contado por aí e a forma como Heródoto julga que ele deveria ser interpretado. Com base na focalização quando ela ocorre na própria pessoa autoral de Heródoto, especialmente quando ele se apresenta ostensivamente como autor crítico, 
há $100 \%$ de consistência no tratamento de mythos e logos na narrativa. Portanto, esse tratamento já revela uma abordagem sofisticada e intencional que expressa um contraste entre os conceitos representados por esses dois termos.

\section{REFERÊNCIAS BIBLIOGRÁFICAS}

BARAGWANATH, Emily; BAKKER, Mathieu de (eds.). Myth, Truth and Narrative in Herodotus. Oxford: Oxford University Press, 2012.

BRANSCOME, David. Textual Rivals: Self-Representation in Herodotus' Histories. Ann Arbor: The University of Michigan Press, 2013.

CHANTRAINE, Pierre. Dictionnaire Étymologique de la Langue Grecque: Histoire des Mots. Paris: Klincksieck, 1968-1980.

CHERUBIN, Rose. Alētheia from poetry into philosophy: Homer to Parmenides. In: WIANS, William (ed.). Logos and Muthos: Philosophical Essays in Greek Literature. Albany: SUNY Press, 2009, p. 51-72.

CONDILO, Camila. Agonistic intertextuality: Herodotus' engagement with Hecataeus on genealogies. Journal of Ancient History, 5(2), p. 228-279, 2017.

FLORY, Stewart. The Archaic Smile of Herodotus. Detroit: Wayne State University Press, 1987.

FOWLER, Robert. Gods in early Greek historiography. In: BREMMER, JAN N; ERSKINE, A (eds.). The Gods of Ancient Greece: Identities and Transformations. Edinburgh: Edinburgh University Press, 2010, p. 318-334.

FOWLER, Robert. Mythos and Logos. Journal of Hellenic Studies, 131, p. 45-66, 2011. 
GAGARIN, Michael. Probability and persuasion: Plato and early Greek rhetoric. In: IAN WORTHINGTON (ed.). Persuasion: Greek Rhetoric in Action. London: Routledge, 1994, p. 46-68.

GOLDHILL, Simon. The Invention of Prose. Oxford: Oxford University Press, 2002.

GRIMALDI, W.M.A. Semeion, Tekmerion, Eikos in Aristotle's Rhetoric. The American Journal of Philology, 101(4), p. 383-398, 1980.

HARRISON, T. Divinity and History: The Religion of Herodotus. Oxford: Oxford University Press, 2000.

HARRISON, Thomas. Truth and lies in Herodotus' Histories. In: KARAGEORGHIS, Vasos, TAÏPHAKOS, Ioannis (eds.). The World of Herodotus. Proceedings of an International Conference Held at the Foundation Anastasios G. Leventis, Nicosia, September 18-21, 2003, and Organized by the Foundation Anastasios G. Leventis and the Faculty of Letters, University of Cyprus. Nicosia: The Foundation, 2004 , p. 255-263.

JONG, Irene de. Herodotus. In: de JONG, Irene; NÜNLIST, René; BOWIE, Angus (eds.) Narrators, Narratees, and Narratives in Ancient Greek Literature. Leiden/ Boston: Brill, 2004, p. 101-114.

KRAUS, M. Nothing to do with Truth? Eikós in early Greek rhetoric and philosophy. Papers on Rhetoric VII, p. 129150, 2006.

LATEINER, Donald. The Historical Method of Herodotus. Toronto/Buffalo/London: University of Toronto Press, 1989.

LESHER, J. H. Early interest in knowledge. In: A. A. LONG (ed.) The Cambridge Companion to Early Greek Philosophy. Cambridge: Cambridge University Press, 1999, p. 225-249. 
LIMA, Paulo Butti de. L'Inchiesta e la Prova: Immagine Storiografica, Pratica Giuridica e Retorica nella Grecia Classica. Torino: Einaudi, 1996.

MUNSON, Rosaria. Herodotus and the heroic age: The case of Minos. In: EMILY; de BAKKER, Mathieu (eds.). Myth, Truth and Narrative in Herodotus. Oxford: Oxford University Press, 2012, p. 195-212.

THOMAS, Rosalind. Herodotus and Eastern myths and logoi: Deioces the Mede and Pythius the Lydian. In: Baragwanath, EMILY; de BAKKER, Mathieu (eds.). Myth, Truth and Narrative in Herodotus. Oxford: Oxford University Press, 2012, p. 233-253.

VANNICELLI, Pietro. The mythical origins of the medes and the Persians. In: Baragwanath, EMILY; de BAKKER, Mathieu (eds.). Myth, Truth and Narrative in Herodotus. Oxford: Oxford University Press, 2012, p. 255-268.

VARTO, Emily Karen. Early Greek Kinship. Thesis (PhD in Classics). University of British Columbia, Vancouver, 2009.

\section{AGRADECIMENTOS E INFORMAÇŌES}

\section{Camila Condilo}

camcondilo@cantab.net

Pós-doutoranda em História - Bolsista FAPESP

Universidade de São Paulo

Departamento de História e Geografia

Av. Prof. Lineu Prestes, 338, Butantã

05508-000 - São Paulo - São Paulo

Brasil 